\title{
Use of preoperative gabapentin significantly reduces postoperative opioid consumption: a meta-analysis
}

\author{
Sudha Arumugam' \\ Christine SM Lau', \\ Ronald S Chamberlain ${ }^{1-3}$ \\ 'Department of Surgery, Saint \\ Barnabas Medical Center, Livingston, \\ NJ, USA; ${ }^{2}$ Saint George's University \\ School of Medicine, Grenada, West \\ Indies; ${ }^{3}$ Department of Surgery, \\ Rutgers University, New Jersey \\ Medical School, Newark, NJ, USA
}

\author{
This article was published in the following Dove Press journal: \\ Journal of Pain Research \\ 12 September 2016 \\ Number of times this article has been viewed
}

Correspondence: Ronald S Chamberlain Department of Surgery, Saint Barnabas Medical Center, 94 Old Short Hills Road, Livingston, NJ 07039, USA

Tel + I 9733225195

Fax + I 973322 247|

Email rchamberlain@barnabashealth.org
Objectives: Effective postoperative pain management is crucial in the care of surgical patients. Opioids, which are commonly used in managing postoperative pain, have a potential for tolerance and addiction, along with sedating side effects. Gabapentin's use as a multimodal analgesic regimen to treat neuropathic pain has been documented as having favorable side effects. This meta-analysis examined the use of preoperative gabapentin and its impact on postoperative opioid consumption.

Materials and methods: A comprehensive literature search was conducted to identify randomized control trials that evaluated preoperative gabapentin on postoperative opioid consumption. The outcomes of interest were cumulative opioid consumption following the surgery and the incidence of vomiting, somnolence, and nausea.

Results: A total of 1,793 patients involved in 17 randomized control trials formed the final analysis for this study. Postoperative opioid consumption was reduced when using gabapentin within the initial 24 hours following surgery (standard mean difference $-1.35,95 \%$ confidence interval $[\mathrm{CI}]:-1.96$ to $-0.73 ; P<0.001)$. There was a significant reduction in morphine, fentanyl, and tramadol consumption $(P<0.05)$. While a significant increase in postoperative somnolence incidence was observed (relative risk $1.30,95 \% \mathrm{CI}: 1.10-1.54, P<0.05$ ), there were no significant effects on postoperative vomiting and nausea.

Conclusion: The administration of preoperative gabapentin reduced the consumption of opioids during the initial 24 hours following surgery. The reduction in postoperative opioids with preoperative gabapentin increased postoperative somnolence, but no significant differences were observed in nausea and vomiting incidences. The results from this study demonstrate that gabapentin is more beneficial in mastectomy and spinal, abdominal, and thyroid surgeries. Gabapentin is an effective analgesic adjunct, and clinicians should consider its use in multimodal treatment plans among patients undergoing elective surgery.

Keywords: gabapentin, preemptive analgesia, opioid, postoperative pain

\section{Introduction}

In the United States, 51.4 million inpatient surgeries are performed annually and postoperative pain is experienced by as much as $75 \%$ of patients. ${ }^{1-3}$ Effective postoperative pain management following surgery is critical. Inadequate postoperative pain management can negatively impact the patient's health, recovery, and overall experience. ${ }^{4}$ In addition to immediate discomfort, untreated pain is associated with increased morbidity and mortality and decreased quality of life. ${ }^{4}$ Furthermore, chronic postsurgical pain, pain that lasts 2 months and is not attributable to a preexisting medical condition, can develop. ${ }^{5}$ While the majority of surgical patients recover and return to a functional status, some patients are more likely to develop long-term opioid use 
and chronic postsurgical pain. ${ }^{6,7}$ Following limb amputations, breast cancer surgeries, and heart bypass surgeries, the incidence of postsurgical pain is especially high. ${ }^{8}$

Opioids are extremely effective in managing postsurgical pain but have been documented as having an association with somnolence, respiratory depression, hypotension and bradycardia, nausea and vomiting, pruritus, and constipation. ${ }^{9}$ Antihistamines, which are frequently used to treat nausea and pruritus, further worsen the sedation and respiratory depression. ${ }^{10}$ Respiratory depression has been reported to affect patients treated using analgesia pumps that are patient controlled. ${ }^{11,12}$ Given the frequency of opioid-related complications, high patient morbidity as well as prolonged duration of hospitalization, and higher health care costs, effective methods to minimize postoperative opioid consumption is required. ${ }^{13}$

Multimodal analgesia techniques have been researched extensively and implemented by many institutions as standard postoperative care management. ${ }^{14}$ By utilizing multiple medications and therapies that act by different mechanisms of actions within the central and peripheral nervous system, multimodal analgesia can provide individualized targeted patient therapy by taking into account pharmacogenetics such as single gene allelic differences and medication responses to reduce the consumption of opioids and the associated side effects. ${ }^{15,16}$ One such drug is gabapentin that has antihyperalgesic properties. Gabapentin's antihyperalgesic effects result from its action in the dorsal root ganglia and spinal cord. ${ }^{17}$ The safety profile of gabapentin has few associated adverse side effects. ${ }^{18}$ Alayed et al ${ }^{19}$ reported significant reductions in morphine consumption with the use of gabapentin (standard mean difference [SMD] -1.45, $95 \%$ confidence interval $[\mathrm{CI}]:-1.79$ to $-1.11 ; P<0.05)$ in a review including four randomized control trials (RCTs) involving 190 patients undergoing abdominal hysterectomy. A significant number of RCTs have demonstrated conflicting results in the use of preoperative gabapentin. ${ }^{19}$ Bharti et $\mathrm{al}^{20}$ studied gabapentin administration among patients $(n=40)$ undergoing mastectomy (20 received gabapentin and 20 received placebo) and demonstrated a reduction in the amount of morphine required during the initial 24 hours following surgery with the use of gabapentin $(2.1 \pm 2.2 \mathrm{mg}$ vs $4.9 \pm 3.4 \mathrm{mg}, P=0.06)$. Conversely, Kinney et $\mathrm{al}^{21} \mathrm{dem}-$ onstrated no significant difference in cumulative morphine consumption during the initial 24 hours following surgery (111.9 mg vs $118.1 \mathrm{mg}, P=0.340$ ) in an RCT among patients undergoing thoracotomy $(n=120 ; 57$ patients received gabapentin and 63 patients received placebo).
Given the high incidence of adverse events associated with opioid medications, this meta-analysis examined the use of preoperative gabapentin and its impact on postoperative opioid consumption and opioid use after surgery and the incidence of vomiting, somnolence, and nausea.

\section{Materials and methods Study selection}

RCTs that evaluated preoperative gabapentin on postoperative opioid consumption were identified using PubMed, Google Scholar, and the Cochrane Central Register of Controlled Trials (1966-2016). RCTs written in English were included in this study. Only the most updated and recent report of the RCT was included in the final analysis when duplicate publications existed. The inclusion criteria of the RCTs were patients $>18$ years, patient undergoing inpatient surgeries (open or laparoscopic) under general anesthesia, preoperative administration of gabapentin irrespective of dose and duration before surgery (compared to a placebo), and trials reporting opioid consumption as the primary outcome. RCTs reporting only postoperative use of gabapentin or in addition to a preoperative dosing were excluded from the analysis. A combination of keywords searched included "gabapentin", "preemptive analgesia", "postoperative pain", and "opioid consumption".

\section{Data extraction}

The Preferred Reporting Items for Systematic Reviews and Meta-Analyses guidelines were employed for data extraction, systematic review, and meta-analysis. All RCTs were assessed for data relevant to patients undergoing elective surgery, the intervention utilized, control or placebo groups, primary outcome measures, and methods. Figure 1 details the characteristics of all published RCTS included in the final analysis. The primary outcome analyzed was opioid consumption during the initial postoperative period ( 24 hours), while the secondary outcomes were incidence of vomiting, somnolence, and nausea.

\section{Statistical analysis}

In all, 95\% CI and relative risk (RR) were calculated for vomiting, somnolence, and nausea incidences, while 95\% CI and SMDs were calculated for cumulative consumption of opioids during the initial 24 hours following surgery. A continuity correction factor of 0.5 was used to calculate $R R$ and variance in RCTs that included zero events. RCTs in which zero events occurred in both gabapentin and control arms were not calculable and were excluded from the current study. A fixed-effect 


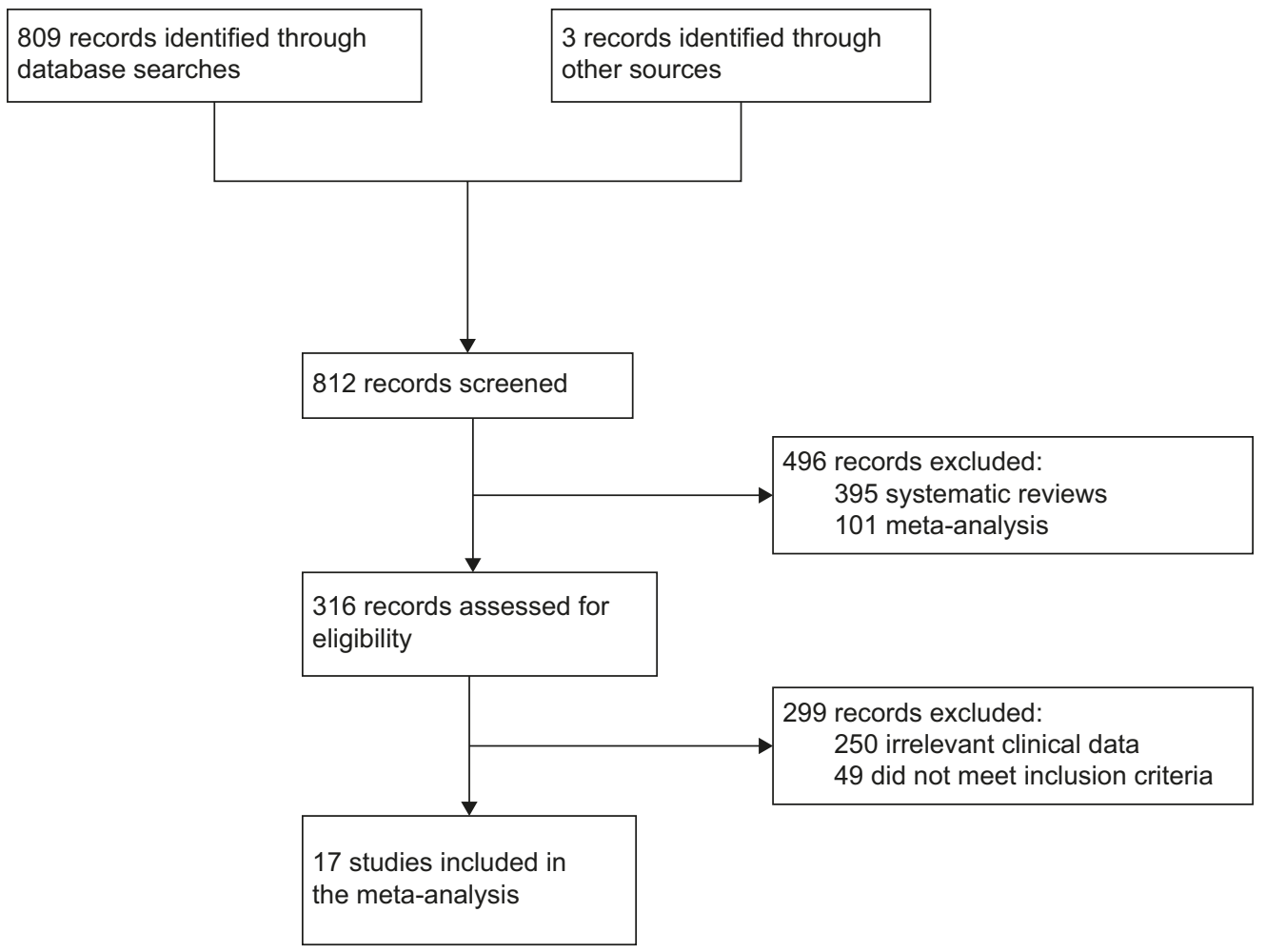

Figure I A CONSORT diagram detailing the study selection process.

model and a random-effects model were used following an evaluation of the heterogeneity in the included RCT. Statistical heterogeneity was assessed using the $I^{2}$ statistic and Cochran's Q statistic. While a fixed-effect model was utilized in the absence of heterogeneity, a random-effects model was used when there existed heterogeneity. Heterogeneity was assumed to be statistically significant when $I^{2}>50$ or $P<0.05$. A funnel plot was used to evaluate publication bias and further evaluated using Begg's and Egger's tests. A subgroup analysis was performed using opioid type (fentanyl, tramadol, or morphine), type of surgery, and dose of gabapentin administered. A two-tailed $P$-value of $<0.05$ was considered to be statistically significant. All statistical analyses for the current study were performed using the Comprehensive Meta-Analysis software Version 3 (Biostat, Englewood, NJ, USA).

\section{Results}

Table 1 details the selection process of the included RCTs. In all, 812 relevant citations were identified using the search strategy. More than half of the citations $(n=496)$ were excluded. Of the 316 citations assessed for eligibility, an additional 299 citations were excluded based on irrelevant clinical data and failing to meet the inclusion criteria.

The final analysis included a total of 17 RCTs, involving 1,793 patients. Of the 1,793 patients, 895 received gabapentin, while the remaining 898 received a control.

\section{Gabapentin effects on opioid consumption}

Opioid consumption was reported in all 17 trials among patients in the gabapentin and control groups. Significant heterogeneity was not observed between trials $\left(I^{2}=95.45\right.$, $P<0.001)$. Compared to the control group, a statistically significant decrease in cumulative opioid consumption using gabapentin was observed (SMD $-1.35,95 \% \mathrm{CI}:-1.96$ to $-0.73 ; P<0.001$; Figure 2).

\section{Subgroup analyses}

The results demonstrated a statistically significant reduction in cumulative consumption of tramadol (SMD $-1.57,95 \%$ CI: -2.82 to $-0.33 ; P<0.05$ ), fentanyl (SMD $-2.54,95 \% \mathrm{CI}$ : -3.78 to $-1.31 ; P<0.001$ ), and morphine (SMD $-0.93,95 \%$ CI: -1.41 to $-0.44 ; P<0.001$ ) using gabapentin (Figure 3 ).

A significant reduction was observed in cumulative morphine following abdominal hysterectomy (SMD $-3.26,95 \% \mathrm{CI}:-4.11$ to $-2.41 ; P<0.001)$, breast cancer surgery (SMD $-1.17 ; 95 \% \mathrm{CI}:-1.63$ to $-0.71 ; P<0.001$ ), cholecystectomy (SMD $-2.80,95 \% \mathrm{CI}:-3.71$ to -1.89 ; $P<0.001$ ), orthopedic surgeries (SMD $-0.86,95 \% \mathrm{CI}$ : -1.54 to $-0.19 ; P=0.012$ ), spinal surgeries (SMD -2.66 , 95\% CI: -3.43 to $-1.90 ; P<0.001)$, and thyroid surgeries (SMD $-1.63,95 \% \mathrm{CI}:-2.16$ to $-1.09 ; P<0.001$ ). A slight reduction was observed in postoperative opioid 
Table I Characteristics of RCTs evaluating preoperative gabapentin use on postoperative opioid consumption

\begin{tabular}{|c|c|c|c|c|c|}
\hline Author (year) & Type of surgery & Number of subjects (gabapentin/control) & Dose (mg) & Control & Type of opioid \\
\hline Pandey et al $(2004)^{34}$ & Cholecystectomy & $153 / 153$ & 300 & Placebo & Fentanyl \\
\hline Pandey et al $(2004)^{23}$ & Orthopedic surgery & $28 / 28$ & 300 & Placebo & Fentanyl \\
\hline Turan et al $(2004)^{35}$ & Abdominal hysterectomy & $25 / 25$ & 1,200 & Placebo & Tramadol \\
\hline Turan et al $(2004)^{36}$ & Orthopedic surgery & $25 / 25$ & 1,200 & Placebo & Morphine \\
\hline Radhakrishnan et al $(2005)^{37}$ & Abdominal hysterectomy & $30 / 30$ & 800 & Placebo & Morphine \\
\hline Adam et al $(2005)^{38}$ & Orthopedic surgery & $30 / 30$ & 1,200 & Placebo & Morphine \\
\hline Al-Mujadi et al $(2006)^{39}$ & Thyroid surgery & $37 / 35$ & 1,200 & Placebo & Morphine \\
\hline Pandey et al $(2006)^{40}$ & Cholecystectomy & $125 / 125$ & 600 & Placebo & Fentanyl \\
\hline Montazeri et al $(2007)^{4 !}$ & Orthopedic surgery & $35 / 35$ & 300 & Placebo & Morphine \\
\hline Grover et al $(2009)^{42}$ & Total mastectomy & $25 / 21$ & 600 & Placebo & Morphine \\
\hline Srivastava et al $(2010)^{43}$ & Cholecystectomy & $60 / 60$ & 600 & Placebo & Tramadol \\
\hline Moore et al $(20 \mathrm{II})^{22}$ & Cesarean section & $21 / 23$ & 900 & Placebo & Morphine \\
\hline Deniz et al $(2012)^{44}$ & Prostatectomy & $25 / 26$ & 900 & Placebo & Tramadol \\
\hline Short et al $(2012)^{45}$ & Cesarean section & $42 / 42$ & 300 & Placebo & Morphine \\
\hline Short et al $(2012)^{45}$ & Cesarean section & $42 / 42$ & 600 & Placebo & Morphine \\
\hline Kinney et al $(2012)^{2 l}$ & Thoracotomy & $57 / 63$ & 600 & Placebo & Morphine \\
\hline Bharti et al $(2013)^{20}$ & Mastectomy & $20 / 20$ & 600 & Placebo & Morphine \\
\hline
\end{tabular}

Abbreviation: RCT, randomized control trial.

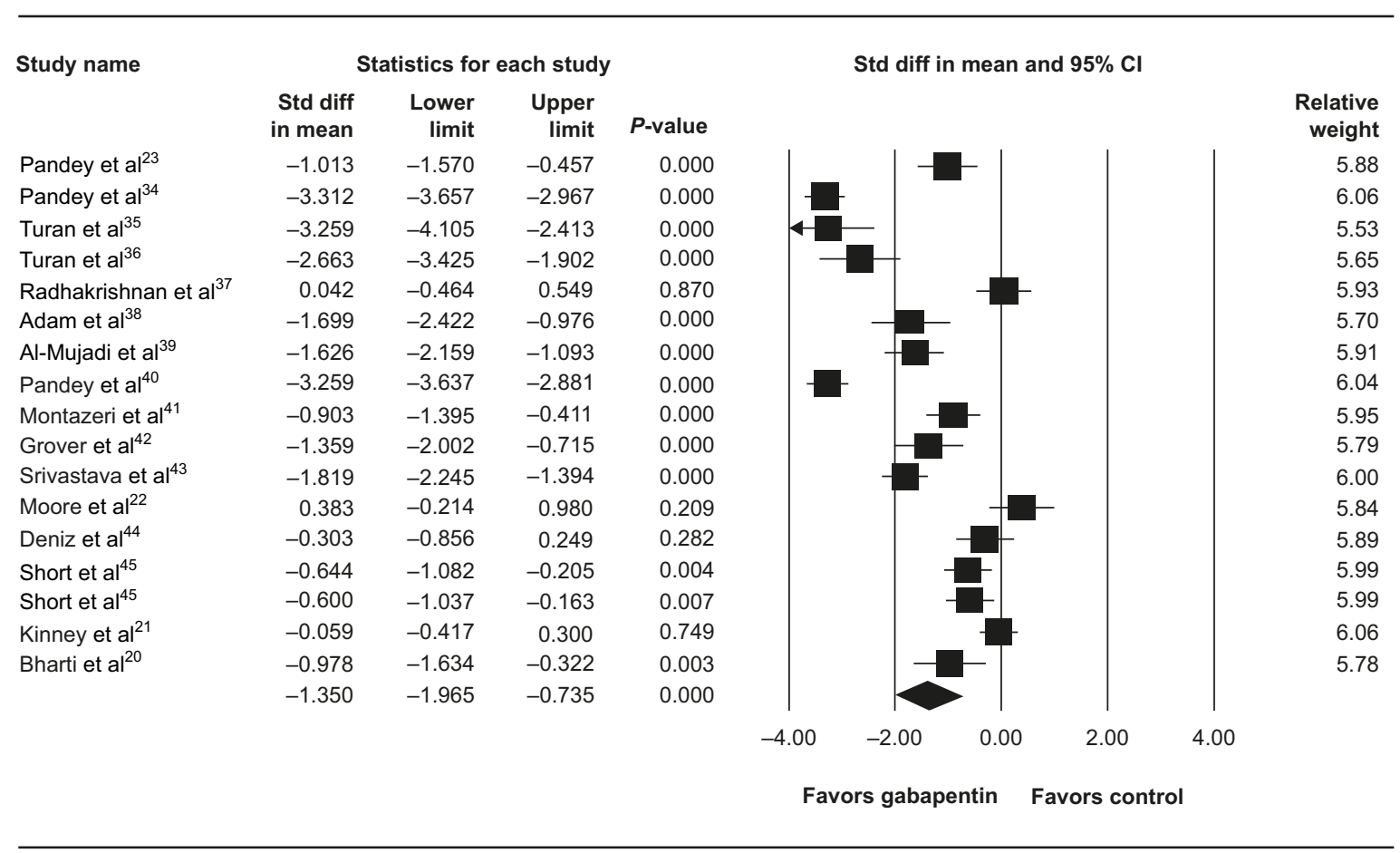

Figure 2 A forest plot evaluating the standardized difference in mean in postoperative opioid consumption with the use of gabapentin compared to control. Abbreviations: Std diff, standard difference; $\mathrm{Cl}$, confidence interval.

consumption following caesarian sections (SMD -0.32 , 95\% CI: $-0.90-0.26 ; P=0.279$ ), prostatectomy (SMD $-0.30,95 \% \mathrm{CI}:-0.86-0.25 ; P=0.282)$, and thoracotomy (SMD -0.06; 95\% CI: $-0.42-0.30 ; P=0.749$ ), but failed to reach statistical significance (Figure 4 ).

A subgroup analysis identified that gabapentin significantly reduced total cumulative morphine consumption at $300 \mathrm{mg}$ (SMD $-1.48,95 \% \mathrm{CI}$ : -2.90 to $-0.05 ; P=0.04)$,
$600 \mathrm{mg}$ (SMD $-1.35,95 \% \mathrm{CI}:-2.41$ to $-0.28 ; P=0.01)$, and $1,200 \mathrm{mg}$ (SMD $-2.27,95 \% \mathrm{CI}:-3.02$ to $-1.52 ; P<0.001$ ). Heterogeneity was statistically significant between groups, $P<0.001$ (Figure 5).

Meta-regression analyses identified a statistical association between postoperative opioid consumption and gabapentin dosage (slope 95\% CI: -0.00061 [-0.00021-0.00101], $P=0.00288$, compared with slope $=0$ ). 


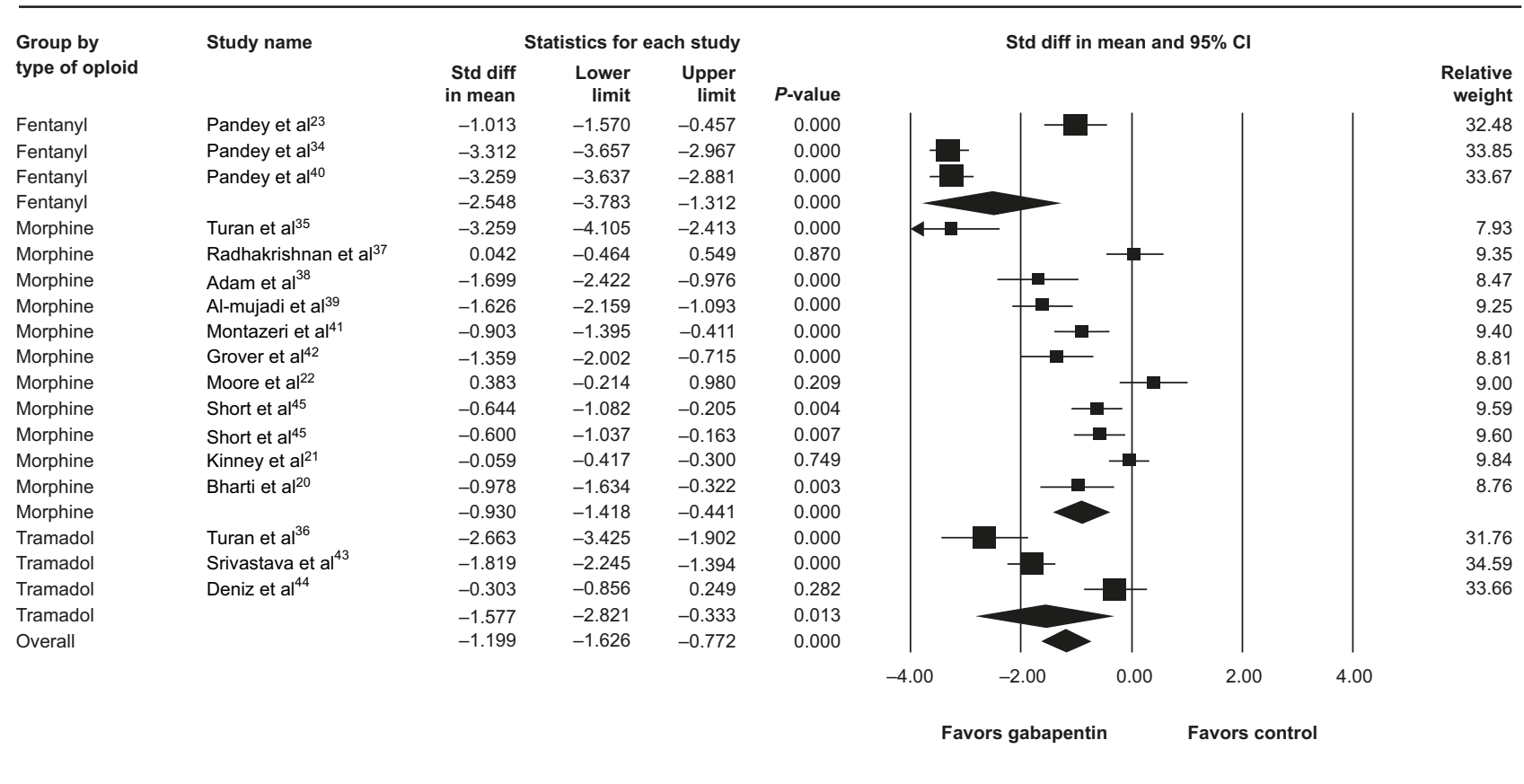

Figure 3 A forest plot evaluating the SMD in postoperative opioid consumption with the use of gabapentin compared to control: a subgroup analysis by type of opioid. Abbreviations: SMD, standard mean difference; Std diff, standard difference; Cl, confidence interval.

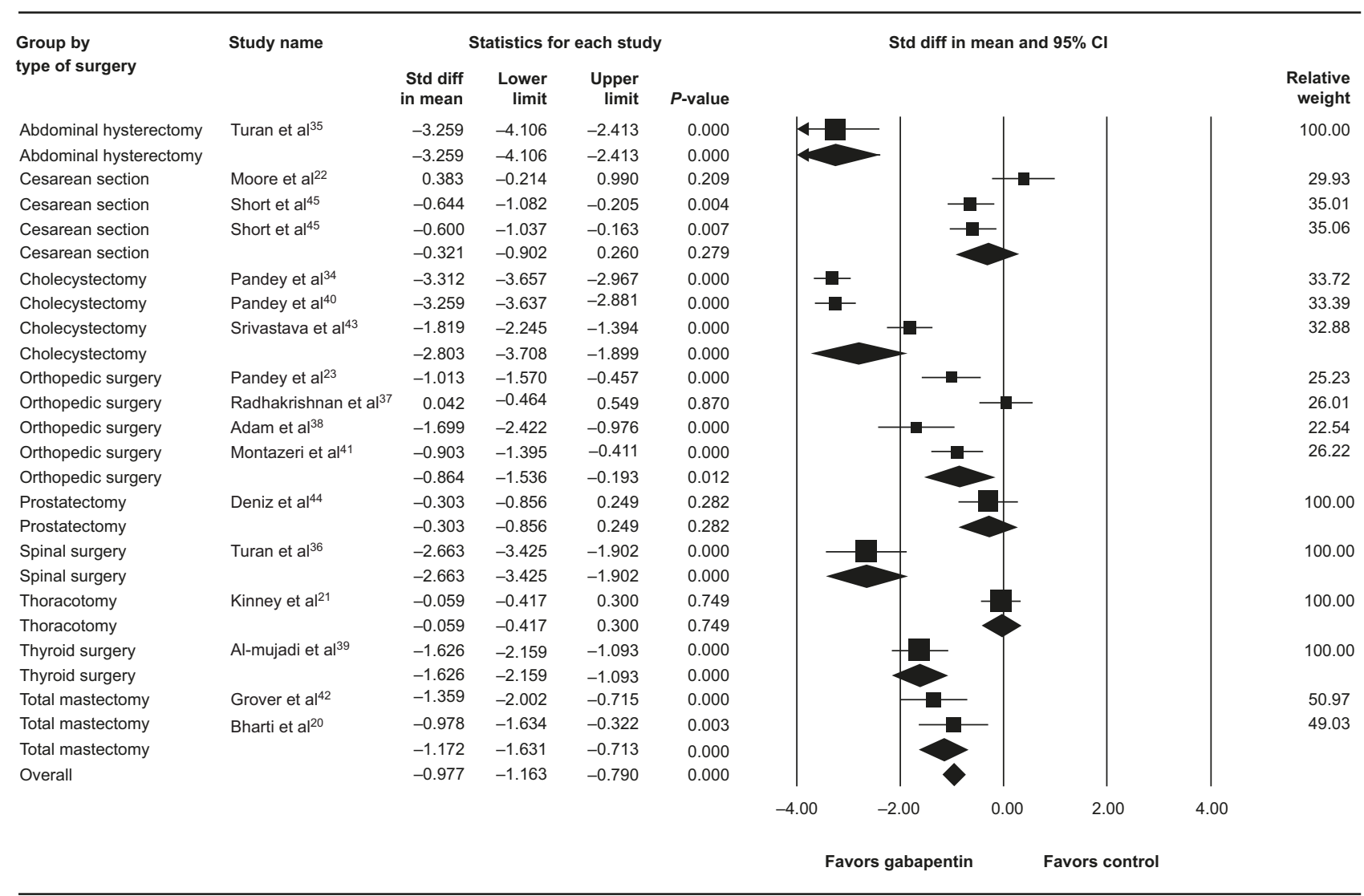

Figure $4 \mathrm{~A}$ forest plot evaluating the SMD in postoperative opioid consumption with the use of gabapentin compared to control: a subgroup analysis by type of surgery.

Abbreviations: SMD, standard mean difference; Std diff, standard difference; Cl, confidence interval. 


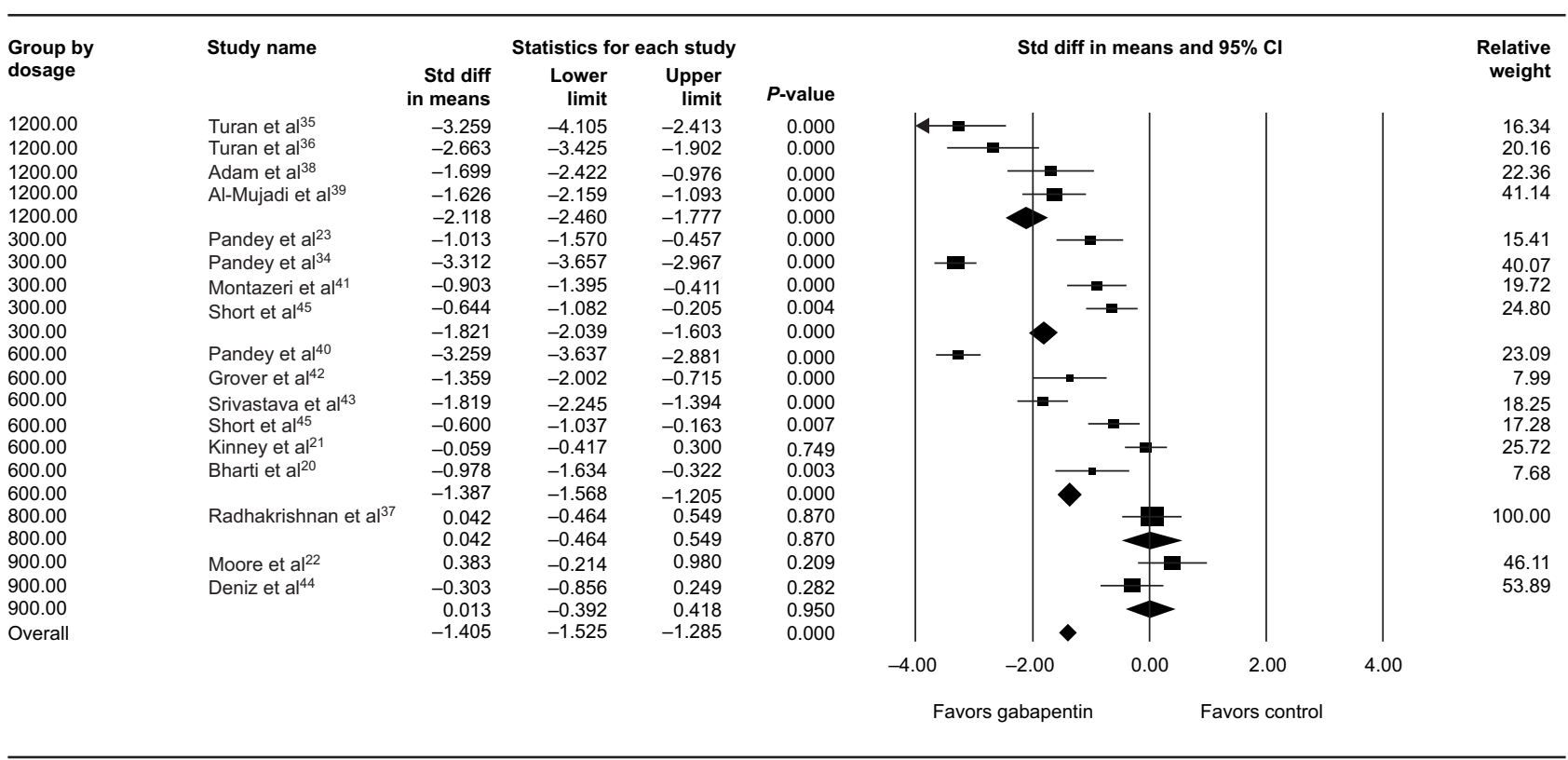

Figure $5 \mathrm{~A}$ forest plot evaluating the SMD in postoperative opioid consumption with the use of gabapentin compared to control: a subgroup analysis by dose. Abbreviations: SMD, standard mean difference; Std diff, standard difference; Cl, confidence interval.

\section{Effect of gabapentin on secondary outcomes}

Nausea, vomiting, and somnolence incidence rates in the gabapentin and control groups were reported in ten and eleven trials, respectively. A fixed-effect model was assumed since heterogeneity was not observed between trials $\left(P=0.45, I^{2}=0.000\right)$. Statistically significant differences in nausea or vomiting between the gabapentin and control groups ( $\mathrm{RR}=1.08,95 \%$ CI: $0.87-1.34, P=0.44$ and $\mathrm{RR}=0.839,95 \% \mathrm{CI}: 0.61-1.51$, $P=0.277$, respectively) were not observed in the meta-analysis (Figures 6 and 7). Eight trials reported data on the incidence of postoperative somnolence. Between trials, the results demonstrated statistically significant heterogeneity $(P=0.001$, $P^{2}=68.69$ ), and therefore, a random-effects model was assumed. Gabapentin significantly increased somnolence incidence (RR $=1.304,95 \%$ CI: $1.104-1.54, P<0.05$; Figure 8). ${ }^{22,23}$

\section{Publication bias}

Egger's and Begg's tests were performed to calculate and evaluate publication bias for the primary outcome. Evidence of asymmetry was not observed on the funnel plot (Figure 9). The results demonstrated that publication bias was not statistically significant by Egger's test or Begg's test, $P=0.57$ and $P=0.53$, respectively.

\section{Discussion}

Adequate postoperative pain management is a crucial component in surgical patient care. Effective postoperative pain management not only improves the patient's level of comfort and satisfaction but also is associated with earlier mobilization, fewer cardiopulmonary complications, reduced risk of thromboembolism, earlier return of bowel function, faster recovery, and reduced hospital costs..$^{4,24,25}$ Traditionally, opioid analgesics that act on mechanisms associated with pain perception have been used in managing postoperative pain. While opioid medications, including morphine, hydromorphone, fentanyl, and meperidine, are very effective analgesics, they are also associated with numerous adverse side effects that include somnolence, respiratory depression, cardiac instability including hypotension and bradycardia, and nausea, vomiting, pruritus, and constipation. ${ }^{13}$

Multimodal pain management aims for additive or synergistic effects by utilizing analgesic medications of various classes that have differing pharmacologic mechanisms of actions in the nervous system. ${ }^{26}$ By combining multiple drugs from different classes, multimodal pain management regimens aim to provide adequate pain management, while reducing the amount of required postoperative opioid use and its associated adverse effects.

Gabapentin is commonly indicated in the treatment of seizures. ${ }^{27}$ Gabapentin, which acts on the nociceptive processes involved in central sensitization, has been shown to reduce hypersensitivity associated with nerve injury (hyperalgesia) and postoperative pain and inflammation in animal models. ${ }^{28}$ Interestingly, gabapentin's antiemetic effects were first recognized when studies involving breast 


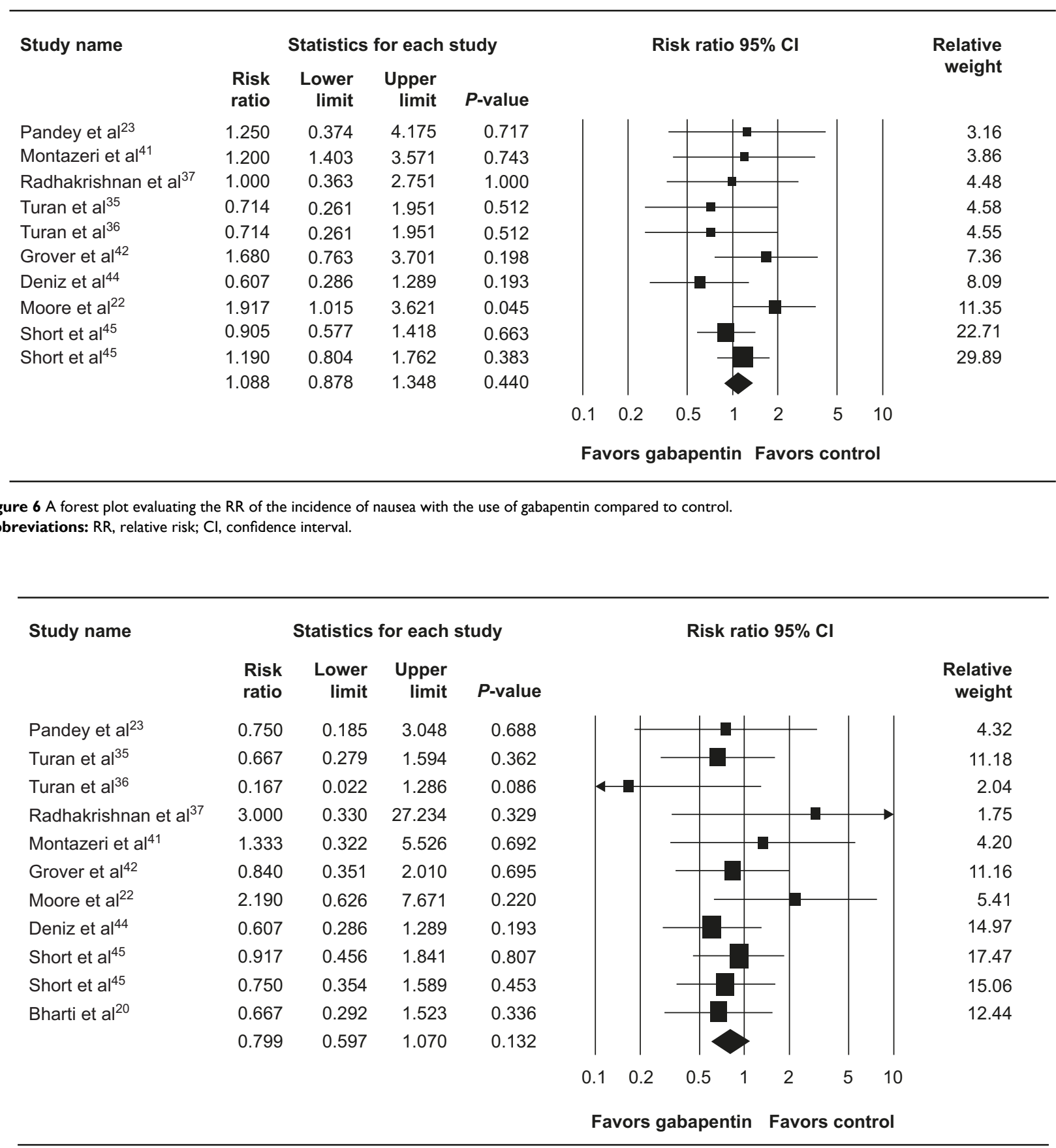

Figure $7 \mathrm{~A}$ forest plot evaluating the RR of the incidence of vomiting with the use of gabapentin compared to control. Abbreviations: $\mathrm{RR}$, relative risk; $\mathrm{Cl}$, confidence interval.

cancer patients demonstrated a significant reduction in chemotherapy-induced nausea with the use of gabapentin. ${ }^{29}$ Gabapentin's antiemetic effects are likely attributable to the reduced tachykinin neurotransmission and the direct reduction in postoperative opioid consumption..$^{29,30}$

The results demonstrated a statistically significant reduction in the postoperative cumulative consumption of fentanyl, morphine, and tramadol during the initial 24 hours following surgery with the administration of preoperative gabapentin. Significant reductions in postoperative opioid consumption were observed following abdominal hysterectomy, breast cancer surgery, cholecystectomy, orthopedic surgeries, spinal surgeries, and thyroid surgeries. Although not significant, a small reduction in postoperative opioid consumption was observed following caesarian sections, prostatectomy, and thoracotomy. There was no significant differences observed in vomiting and nausea incidences with the use of gabapentin; however, a recent meta-analysis by 


\begin{tabular}{|c|c|c|c|c|}
\hline \multirow[t]{2}{*}{ Study name } & \multicolumn{4}{|c|}{ Statistics for each study } \\
\hline & $\begin{array}{l}\text { Risk } \\
\text { ratio }\end{array}$ & $\begin{array}{l}\text { Lower } \\
\text { limit }\end{array}$ & $\begin{array}{r}\text { Upper } \\
\text { limit }\end{array}$ & $P$-value \\
\hline Pandey et $\mathrm{al}^{23}$ & 10.400 & 4.271 & 25.323 & 0.000 \\
\hline Turan et $\mathrm{al}^{35}$ & 3.000 & 0.128 & 70.296 & 0.495 \\
\hline Turan et $\mathrm{al}^{36}$ & 2.000 & 0.194 & 20.671 & 0.561 \\
\hline Radhakrishnan et $\mathrm{al}^{37}$ & 1.000 & 0.066 & 15.260 & 1.000 \\
\hline Pandey et $\mathrm{al}^{40}$ & 2.000 & 0.373 & 10.722 & 0.418 \\
\hline Srivastava et $\mathrm{al}^{43}$ & 1.750 & 0.793 & 3.862 & 0.166 \\
\hline Moore et $\mathrm{al}^{22}$ & 1.340 & 1.042 & 1.724 & 0.023 \\
\hline Short et al ${ }^{45}$ & 1.080 & 0.772 & 1.512 & 0.654 \\
\hline \multirow[t]{2}{*}{ Short et $\mathrm{al}^{45}$} & 1.000 & 0.703 & 1.423 & 1.000 \\
\hline & 1.636 & 1.084 & 2.471 & 0.019 \\
\hline
\end{tabular}

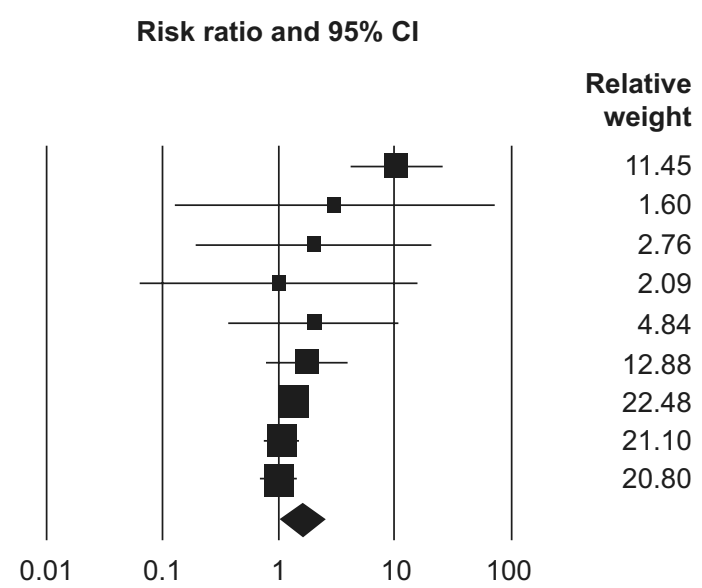

Favors gabapentin Favors control

Figure 8 A forest plot evaluating the RR of the incidence of somnolence with the use of gabapentin compared to control.

Abbreviations: $\mathrm{RR}$, relative risk; $\mathrm{Cl}$, confidence interval.

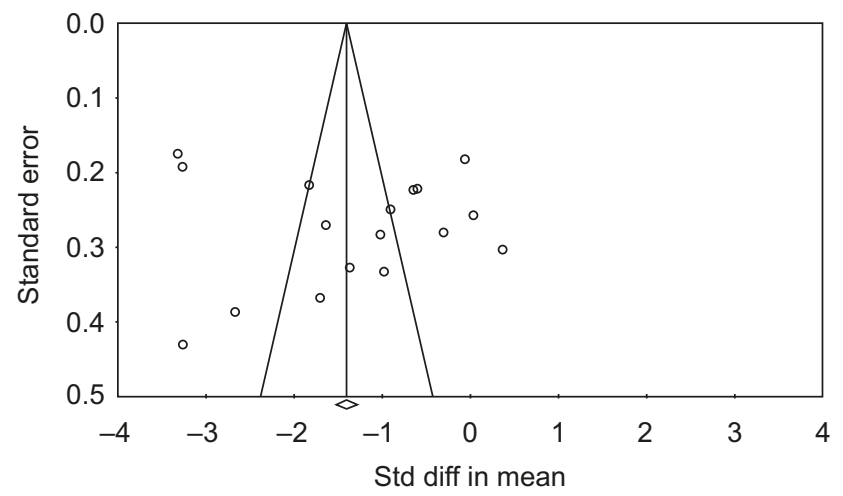

Figure 9 A funnel plot assessing publication bias (analyzing the effect of preoperative gabapentin administration on opioid consumption within the first 24 hours postoperatively).

Abbreviation: Std diff, standard difference.

Grant et al ${ }^{31}$ evaluating the use of preoperative gabapentin on postoperative nausea and vomiting reported statistically significant reductions in postoperative nausea $(\mathrm{RR}=0.76$, 95\% CI: $0.67-0.85, P<0.0001 ; 42$ studies involving 2,349 patients) and vomiting ( $\mathrm{RR}=0.67,95 \% \mathrm{CI}: 0.56-0.80$, $P<0.0001 ; 36$ studies involving 2,024 patients). In all the trials, gabapentin was administered preoperatively as a single oral dose or two divided doses 2-24 hours before surgery at a dose ranging from $300 \mathrm{mg}$ to $1,200 \mathrm{mg}$. This study also identified an association between cumulative gabapentin dose and reduction in morphine consumption. The higher the dose of gabapentin, the greater the reduction in morphine consumption.

Gabapentin has been documented with minimal side effects and is considered a safe and tolerable medication. ${ }^{32}$ The side effects of gabapentin are limited to somnolence, confusion, ataxia, dizziness, nausea, and weight gain. ${ }^{33}$ Nausea and vomiting incidence rates were similar, despite having a reduction in overall opioid consumption and presumed antiemetic property of gabapentin. The findings from the current study demonstrated a slight increase in the incidence of somnolence.

This study contains several limitations. The first is the different opioid and dosage used. Three studies utilized fentanyl and three utilized tramadol, which were converted to their equivalent morphine dose for analysis. Second, details regarding the more common opioid side effects were rarely reported, with the exception of postoperative nausea and vomiting. Additional research is warranted to examine optimal gabapentin dose and frequency regimen to determine the presence of beneficial or resistant interactions between certain opioids and adjuvant gabapentin therapy. Furthermore, the small sample size of most included RCTs $(<50$ patients per study) presented challenges to generalize conclusions and speculate the impact of gabapentin on rare complications such as respiratory depression.

\section{Conclusion}

Preoperative adjunct gabapentin administration significantly reduces opioid consumption within the initial 24 hours following surgery, with similar incidence rates of side effects. The greatest reduction was observed in gynecologic and breast cancers, cholecystectomy, and orthopedic and thyroid surgeries. The observed reduction in postoperative opioid consumption with preoperative gabapentin supports the notion of incorporating gabapentin in the multimodal analgesic treatment plans for postoperative pain management among patients undergoing elective surgery. 


\section{Disclosure}

The authors report no conflicts of interest in this work.

\section{References}

1. Centers for Disease Control and Prevention. National Center for Health Statistics. 2016. Available from: http://www.cdc.gov/nchs/fastats/. Accessed August 3, 2016.

2. Schug SA, Large RG. Economic considerations in pain management. Pharmacoeconomics. 1993;3(4):260-267.

3. Owen H, McMillan V, Rogowski D. Postoperative pain therapy: a survey of patients' expectations and their experiences. Pain. 1990;41(3):303-307.

4. Carr DB, Goudas LC. Acute pain. Lancet. 1999;353(9169):2051-2058.

5. Macrae WA. Chronic post-surgical pain: 10 years on. Br J Anaesth. 2008;101(1):77-86.

6. Searle RD, Simpson MP, Simpson KH, Milton R, Bennett MI. Can chronic neuropathic pain following thoracic surgery be predicted during the postoperative period? Interact Cardiovasc Thorac Surg. 2009;9(6):999-1002.

7. Clarke H, Poon M, Weinrib A, Katznelson R, Wentlandt K, Katz J. Preventive analgesia and novel strategies for the prevention of chronic post-surgical pain. Drugs. 2015;75(4):339-351.

8. Perkins FM, Kehlet H. Chronic pain as an outcome of surgery. A review of predictive factors. Anesthesiology. 2000;93(4):1123-1133.

9. Benyamin R, Trescot AM, Datta S, et al. Opioid complications and side effects. Pain Physician. 2008;11(2 Suppl):S105-S120.

10. Anwari JS, Iqbal S. Antihistamines and potentiation of opioid induced sedation and respiratory depression. Anaesthesia. 2003;58(5):494-495.

11. Ashburn MA, Love G, Pace NL. Respiratory-related critical events with intravenous patient-controlled analgesia. Clin J Pain. 1994;10(1):52-56.

12. Etches RC. Respiratory depression associated with patient-controlled analgesia: a review of eight cases. Can J Anaesth. 1994;41(2):125-132.

13. Oderda GM, Said Q, Evans RS, et al. Opioid-related adverse drug events in surgical hospitalizations: impact on costs and length of stay. Ann Pharmacother. 2007;41(3):400-406.

14. Joshi SS, Jagadeesh AM. Efficacy of perioperative pregabalin in acute and chronic post-operative pain after off-pump coronary artery bypass surgery: a randomized, double-blind placebo controlled trial. Ann Card Anaesth. 2013;16(3):180-185.

15. White PF. Multimodal analgesia: its role in preventing postoperative pain. Curr Opin Investig Drugs. 2008;9(1):76-82.

16. Costantini R, Affaitati G, Fabrizio A, Giamberardino MA. Controlling pain in the post-operative setting. Int J Clin Pharmacol Ther. 2011;49(2):116-127.

17. Chang CY, Challa CK, Shah J, Eloy JD. Gabapentin in acute postoperative pain management. Biomed Res Int. 2014;2014:631756.

18. Bockbrader HN, Wesche D, Miller R, Chapel S, Janiczek N, Burger P. A comparison of the pharmacokinetics and pharmacodynamics of pregabalin and gabapentin. Clin Pharmacokinet. 2010;49(10):661-669.

19. Alayed N, Alghanaim N, Tan X, Tulandi T. Preemptive use of gabapentin in abdominal hysterectomy: a systematic review and meta-analysis. Obstet Gynecol. 2014;123(6):1221-1229.

20. Bharti N, Bala I, Narayan V, Singh G. Effect of gabapentin pretreatment on propofol consumption, hemodynamic variables, and postoperative pain relief in breast cancer surgery. Acta Anaesthesiol Taiwan. 2013;51(1):10-13.

21. Kinney MA, Mantilla CB, Carns PE, et al. Preoperative gabapentin for acute post-thoracotomy analgesia: a randomized, double-blinded, active placebo-controlled study. Pain Pract. 2012;12(3):175-183.

22. Moore A, Costello J, Wieczorek P, Shah V, Taddio A, Carvalho JC. Gabapentin improves postcesarean delivery pain management: a randomized, placebo-controlled trial. Anesth Analg. 2011;112(1):167-173.

23. Pandey CK, Sahay S, Gupta D, et al. Preemptive gabapentin decreases postoperative pain after lumbar discoidectomy. Can J Anaesth. 2004;51(10):986-989.
24. Breivik H. Postoperative pain management: why is it difficult to show that it improves outcome? Eur J Anaesthesiol. 1998;15(6):748-751.

25. Joshi GP, Ogunnaike BO. Consequences of inadequate postoperative pain relief and chronic persistent postoperative pain. Anesthesiol Clin North America. 2005;23(1):21-36.

26. Elvir-Lazo OL, White PF. The role of multimodal analgesia in pain management after ambulatory surgery. Curr Opin Anaesthesiol. 2010;23(6):697-703.

27. McLean MJ, Gidal BE. Gabapentin dosing in the treatment of epilepsy. Clin Ther. 2003;25(5):1382-1406.

28. Mao J, Chen LL. Gabapentin in pain management. Anesth Analg. 2000;91(3):680-687.

29. Guttuso T Jr, Roscoe J, Griggs J. Effect of gabapentin on nausea induced by chemotherapy in patients with breast cancer. Lancet. 2003;361(9370):1703-1705.

30. Felix R, Gurnett CA, De WM, Campbell KP. Dissection of functional domains of the voltage-dependent $\mathrm{Ca}^{2+}$ channel alpha2delta subunit. J Neurosci. 1997;17(18):6884-6891.

31. Grant MC, Lee H, Page AJ, Hobson D, Wick E, Wu CL. The effect of preoperative gabapentin on postoperative nausea and vomiting: a meta-analysis. Anesth Analg. 2016;122(4):976-985.

32. Rivkin A, Rivkin MA. Perioperative nonopioid agents for pain control in spinal surgery. Am J Health Syst Pharm. 2014;71(21):1845-1857.

33. Goa KL, Sorkin EM. Gabapentin. A review of its pharmacological properties and clinical potential in epilepsy. Drugs. 1993;46(3):409-427.

34. Pandey CK, Priye S, Singh S, Singh U, Singh RB, Singh PK. Preemptive use of gabapentin significantly decreases postoperative pain and rescue analgesic requirements in laparoscopic cholecystectomy. Can J Anaesth. 2004;51(4):358-363.

35. Turan A, Karamanlioglu B, Memis D, Usar P, Pamukcu Z, Ture M. The analgesic effects of gabapentin after total abdominal hysterectomy. Anesth Analg. 2004;98(5):1370-1373.

36. Turan A, Karamanlioglu B, Memis D, et al. Analgesic effects of gabapentin after spinal surgery. Anesthesiology. 2004;100(4):935-938.

37. Radhakrishnan M, Bithal PK, Chaturvedi A. Effect of preemptive gabapentin on postoperative pain relief and morphine consumption following lumbar laminectomy and discectomy: a randomized, double-blinded, placebo-controlled study. J Neurosurg Anesthesiol. 2005;17(3):125-128.

38. Adam F, Menigaux C, Sessler DI, Chauvin M. A single preoperative dose of gabapentin ( 800 milligrams) does not augment postoperative analgesia in patients given interscalene brachial plexus blocks for arthroscopic shoulder surgery. Anesth Analg. 2006;103(5):1278-1282.

39. Al-Mujadi H, Refai AR, Katzarov MG, Dehrab NA, Batra YK, Al-Qattan AR. Preemptive gabapentin reduces postoperative pain and opioid demand following thyroid surgery. Can J Anaesth. 2006;53(3):268-273.

40. Pandey CK, Priye S, Ambesh SP, Singh S, Singh U, Singh PK. Prophylactic gabapentin for prevention of postoperative nausea and vomiting in patients undergoing laparoscopic cholecystectomy: a randomized, double-blind, placebo-controlled study. J Postgrad Med. 2006;52(2):97-100.

41. Montazeri K, Kashefi P, Honarmand A. Pre-emptive gabapentin significantly reduces postoperative pain and morphine demand following lower extremity orthopaedic surgery. Singapore Med J. 2007;48(8):748-751.

42. Grover VK, Mathew PJ, Yaddanapudi S, Sehgal S. A single dose of preoperative gabapentin for pain reduction and requirement of morphine after total mastectomy and axillary dissection: randomized placebocontrolled double-blind trial. J Postgrad Med. 2009;55(4):257-260.

43. Srivastava U, Kumar A, Saxena S, Mishra AR, Saraswat N, Mishra S. Effect of preoperative gabapentin on postoperative pain and tramadol consumption after minilap open cholecystectomy: a randomized doubleblind, placebo-controlled trial. Eur J Anaesthesiol. 2010;27(4):331-335.

44. Deniz MN, Sertoz N, Erhan E, Ugur G. Effects of preoperative gabapentin on postoperative pain after radical retropubic prostatectomy. $J$ Int Med Res. 2012;40(6):2362-2369.

45. Short J, Downey K, Bernstein P, Shah V, Carvalho JC. A single preoperative dose of gabapentin does not improve postcesarean delivery pain management: a randomized, double-blind, placebo-controlled dose-finding trial. Anesth Analg. 2012;115(6):1336-1342. 
The Journal of Pain Research is an international, peer reviewed, open access, online journal that welcomes laboratory and clinical findings in the fields of pain research and the prevention and management of pain. Original research, reviews, symposium reports, hypothesis formation and commentaries are all considered for publication.

Submit your manuscript here: https://www.dovepress.com/journal-of-pain-research-journal

The manuscript management system is completely online and includes a very quick and fair peer-review system, which is all easy to use. Visit http://www.dovepress.com/testimonials.php to read real quotes from published authors. 